\title{
Ultrasonographic Assessment of Retroverted Gravid Uterus and First Trimester Pregnancy loss of women in a semi-urban area of Dhaka, Bangladesh
}

\author{
Shamima Nasrin Shadia ${ }^{1, *}$, Sukalyan Kumar Kundu ${ }^{2}$, Md. Delwar Hossain ${ }^{3}$ \\ ${ }^{1}$ Senior Lecturer, Department of Anatomy, Gonoshasthaya Samaj Vittik Medical College, Mirzanagar, \\ Savar, Dhaka, Bangladesh. \\ ${ }^{2}$ Department of Pharmacy, Jahangirnagar University, Savar, Dhaka-1342, Bangladesh. \\ ${ }^{3}$ Professor \& Head of the Department, Gonoshasthaya Samaj Vittik Medical College Mirzanagar, \\ Savar, Dhaka, Bangladesh.
}

*Corresponding Author: Dr Shamima Nasrin Shadia, Senior Lecturer, Department of Anatomy, Gonosashasthya Samaj Vittik Medical College, Mirzanagar, Savar, Dhaka, Bangladesh. Mobile No.01740549964, E-mail: nas_cbmc@yahoo.com

Submission Date: 03/05/2021 Acceptance Date: 21/05/2021 Published Date: 29/05/2021

\begin{abstract}
Ultrasonography is a safe and effective method of diagnosing early pregnancy and determining the position of the gravid uterus. In our study, 2080 pregnant women with amenorrhea for three months and a positive pregnancy test were chosen. The study was conducted in the Radiology \& Imaging department of Failaria \& General Hospital from Jan 2016 to Dec 2019. Descriptive statistics were used to compute percentages and averages. Results were presented in tables and charts and expressed as percentages/proportions, means and average. The objective of our study is to investigate the Sonographic findings of first trimester pregnancies detecting the retroverted gravid uterus, normal, abnormal and complicated pregnancies. In the present study out of 2080 pregnancies, we found uterus retroverted in about $7 \%$ of women and only one case of acute retention of urine due to retroverted gravid uterus. Here, the majority of pregnant women were 20-24 years of age, which is $980(47.12 \%)$ and $150(7.21 \%)$ women pregnant at the age of over 35 years. In our study, $190(9.13 \%)$ of the 2080 pregnancies with sonographic diagnosis were fetal losses. The diagnosis of early normal intrauterine pregnancy (IUP) was 1890 (90.87\%), Incomplete abortion 95 (4.57\%), Missed abortion 35 (1.68\%), Blighted ovum 39 (1.88\%), ectopic pregnancy 14 (0.67\%) and Hydatiform mole 7 (0.34\%) cases. If urinary retention due to retroverted gravid uterus, abnormal and complicated pregnancies are diagnosed early and treated properly, it can reduce maternal morbidity and mortality.
\end{abstract}

Keywords: USG, Retroversion, Urinary Retention and Pregnancy Loss 


\section{INTRODUCTION}

Ultrasound is a safe and valuable screening investigation for first-trimester pregnant women which are essential for a series of reasons, including:

- Confirm the location where the baby is growing within intrauterine pregnancy (IUP ) or another site of the abdomen(ectopic pregnancy). ${ }^{[1]-[3]}$

- Estimate the size of the fetus \& the nature of the gestational sac. ${ }^{[1]-[2]}$

- Evaluate the presence of twin pregnancies \& their type of twins that can be identified during the scan. ${ }^{2}$

- Identify the cardiac movement and heartbeat of the fetus. ${ }^{[1]-[2]}$

- Diagnosis of pregnancy loss like missed abortion or presence of any abnormalities. ${ }^{[2],[4]}$

- Evaluate the pelvic organ especially the uterus and ovaries for abnormalities. ${ }^{[2]}$

- Used as an effective tool for lower abdominal pain or $\mathrm{P} / \mathrm{V}$ (per vaginal) bleeding. ${ }^{[1]-[2]}$

Ultrasound is also a very effective diagnostic tool for the identification of the position of the gravid uterus either anteverted or retroverted. The uterus is retroverted in about $11 \%$ of women in early pregnancy. ${ }^{[5]}$ Acute urinary retention due to retroverted gravid uterus is a rare disorder
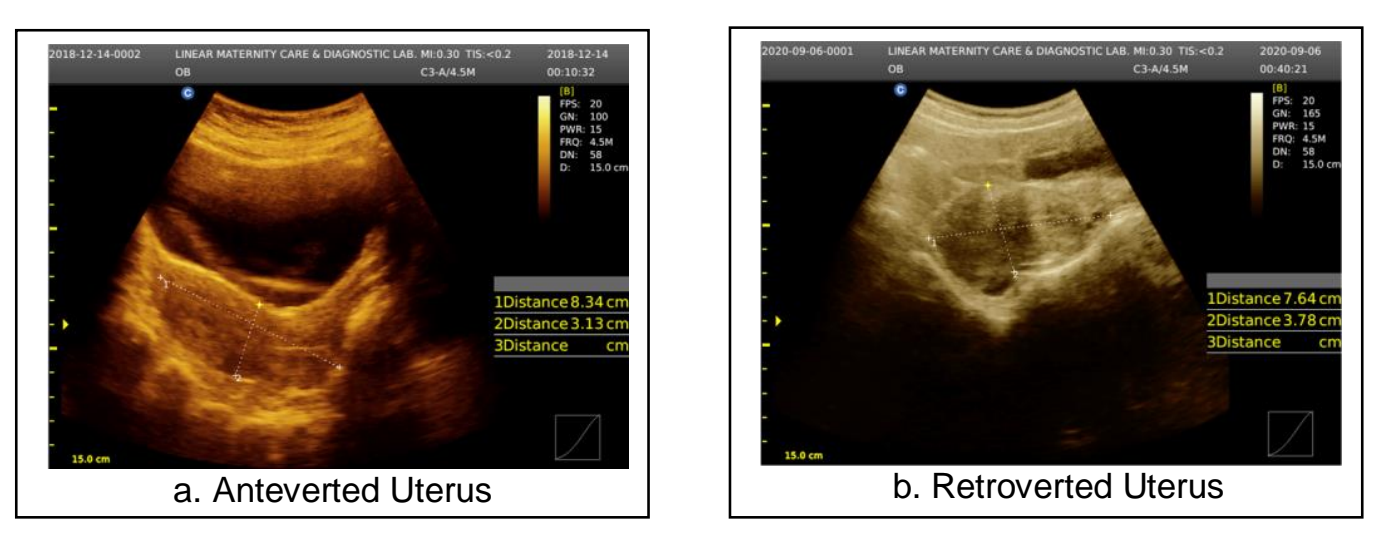

Figure 1. Showing Anteverted Uterus and Retroverted Uterus during USG scanning

\section{MATERIALS AND METHODS}

This is a hospital-based prospective type of study on pregnant women attending the Outpatient Department (OPD) of Failaria \& General Hospital. The study was conducted by the Radiology \& Imaging department of this hospital with duration of 4 years (Jan 2016 to trimester who have amenorrhea for three (3) months and a positive pregnancy test are included in the study.Descriptive statistics were Dec 2019). All pregnant women in their first that is seen in approximately 1 in 3000 pregnancies. ${ }^{[6]}$ It can occur in all trimesters of pregnancy, but most commonly occurs between Retroverted gravid uterus can cause non-specific and generally urinary symptoms resembling dysuria, frequency, urinary incontinence, and urinary infection in early pregnancy. But if it is undiagnosed and pregnancy advances, it can cause severe complications like intrauterine growth retardation (IUGR), oligohydramnios, rupture of the uterus, incision of bladder, cervix, vagina, posterior or anterior uterine wall during caesarean section, urinary retention, renal failure and sepsis. [7] An early diagnosis of the retroverted gravid uterus by pelvic examination and ultrasonographic examination is very important for the treatment of a patient in the early stage and the reduction of late complications in pregnancy. ${ }^{[7],}{ }^{[11]-[12]}$ Most common complication of pregnant women is an early pregnancy loss in $10 \%$ of pregnancies. [13], [14] About $80 \%$ of cases of pregnancy loss occur within the first trimester. ${ }^{[13]-[14]}$ Ultrasonography is helpful to diagnose early pregnancy and pregnancy loss. ${ }^{[15]}$ The aims were our study to investigate the sonographic findings of first trimester pregnancies detecting the retroverted gravid uterus, normal, abnormal and complicated pregnancies. the 10th and 16th weeks of gestation. [7]-[10]

used to compute percentages and averages. Results were presented in tables and charts and expressed as percentages/proportions, means and average.

\section{RESULT}

Figure 1 depicts the positions of the uterus during USG scanning.Figure 2 shows that sonographic findings of Retroverted Uterus were $138(7 \%)$ out of 2080 pregnant women and the remaining 1942 (93\%) are Anteverted Uterus in 
the present study. Table 1 shows demographic and sonographic data of three (3) pregnant women with a complaint of urinary retention. In the present study, we found only 1 (one) case of acute retention of urine due to retroverted gravid uterus.

According to Figure 3, the majority of pregnant women were 20-24 years old (980 (47.12\%), 25-29 years old 520 (25\%), 15-19 years old 230 (11.06\%), 30-34 years old 200 (9.62\%), and $35-39$ years old $150(7.21 \%)$.
Table 2 shows the distribution of cases according to ultrasonographic diagnosis. Normal intrauterine pregnancy (IUP) was diagnosed in 1890 cases $(90.87 \%)$, incomplete abortion in 95 cases $(4.57 \%)$, missed abortion in 35 cases $(1.68 \%)$, blighted ovum in 39 cases $(1.88 \%)$, ectopic pregnancy in 14 cases $(0.67 \%)$, and hydatiform mole in 7 cases $(0.34 \%)$.In our study, the commonest sonographic diagnosis was 1890 $(90.87 \%)$ early normal pregnancy and the incidence of fetal loss was 190 (9.13\%).

\section{Anteverted Uterus $\quad$ Retroverted Uterus}

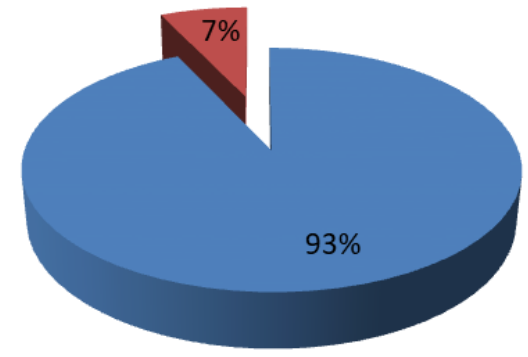

Figure 2. Position of the gravid uterus by ultrasonographic examination

Table 1. Demographic and Sonographic Data of Pregnant women with a complaint of urinary retention

\begin{tabular}{|c|c|c|c|c|c|c|}
\hline $\begin{array}{c}\text { Patient } \\
\text { No. }\end{array}$ & $\begin{array}{c}\text { Age of } \\
\text { pt(Years) }\end{array}$ & $\begin{array}{c}\text { Gravidity/ } \\
\text { Parity }\end{array}$ & $\begin{array}{c}\text { Gestational } \\
\text { age }\end{array}$ & $\begin{array}{c}\text { Position of } \\
\text { Uterus in } \\
\text { USG }\end{array}$ & $\begin{array}{c}\text { Timing of } \\
\text { necessitating } \\
\text { catheterization }\end{array}$ & $\begin{array}{c}\text { History of the } \\
\text { previous } \\
\text { retention of } \\
\text { urine }\end{array}$ \\
\hline 1 & 32 & $2 / 1$ & $13+$ weeks & Anteverted & Early Morning & No \\
\hline 2 & 28 & $1 / 0$ & $10+$ weeks & Retroverted & Midnight & No \\
\hline 3 & 25 & $1 / 0$ & $12+$ weeks & Anteverted & Midnight & Yes \\
\hline
\end{tabular}

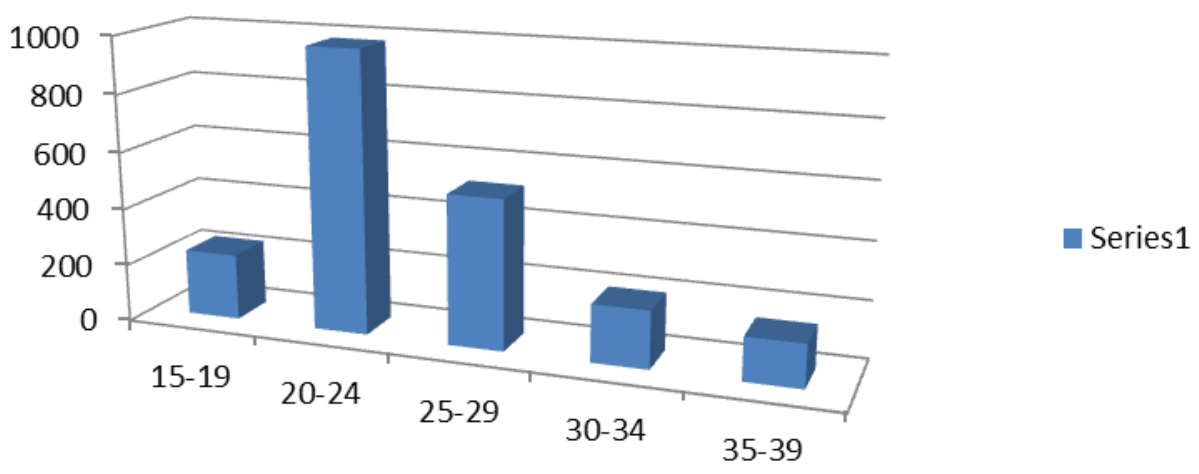

Figure 2. Age group distribution of study Population 
Table 2 Distribution of cases according to ultrasonography diagnosis

\begin{tabular}{|l|l|l|l|}
\hline USG Findings & Status of Fetus & No. of cases & Presentence (\%) \\
\hline $\begin{array}{l}\text { Early } \\
\text { intrauterine pregnancies(IUP) }\end{array}$ & Early normal pregnancy & 1890 & 90.87 \\
\hline Incomplete abortion & Fetal loss & 95 & 4.57 \\
\hline Missed abortion & Fetal loss & 35 & 1.68 \\
\hline Hydatiform mole & Fetal loss & 7 & 0.34 \\
\hline Ectopic pregnancy & Fetal loss & 14 & 0.67 \\
\hline Blighted ovum & Fetal loss & 39 & 1.88 \\
\hline Total & & 2080 & 100.00 \\
\hline $\begin{array}{l}\text { 90.87\% of cases were early normal pregnancy. } \\
\text { 9.13\% of cases were pregnancy losses. }\end{array}$ & \\
\hline
\end{tabular}

\section{DISCUSSION}

In early pregnancy, approximately $11 \%$ of pregnancies may be retroverted uterus but urinary retention due to particularly retroverted gravid uterus is a rare condition. [5]-[6], [16]-[17] Generally, the incidence of acute urinary retention due to retroverted gravid uterus before gestational age of 20 weeks. It occurs when the cervix of the uterus is displaced interiorly and compression to the urethra and bladder neck of pregnant women. [18] In our study, $7 \%$ of pregnancies involve retroverted uterus and only one case was acute urinary retention due to retroverted gravid uterus at 9+ weeks. Similarities were discovered in studies conducted by Silva et al. [11] and Yohannes et al. ${ }^{[19]}$

In this present study, $47.12 \%$ of pregnant women belonged to the age group of 20-24 years. A similar study found in Rozliza et al. found the majority of women (46.2\%). ${ }^{[20]}$ In Bangladesh, a study conducted by Shadia et al, the majority of mothers $(42.59 \%)$ were $20-25$ years of age. ${ }^{[21]}$

In our study, $7.21 \%$ of women were pregnant at the age of over 35 years. Similarly, a study conducted by Cunningham et al. [22] and Newcomb et al. [23] reported almost $10 \%$ of women were at the age of over 35 .

In our study, the incidence of fetal loss was $9.13 \%$. A study conducted by Makrydimas et al. ${ }^{24}$ found $7.5 \%$ fetal loss, which is higher than the present study. Our study is similar to another study where early pregnancy loss occurs in $10 \%$ of pregnancies. [13], [14]

A molar pregnancy occurs in 1 in 1,000 pregnancies in the United States, ${ }^{[25]}$ However, it is higher in Asia, as shown in a different study, with Indonesia [25] accounting for up to $1 \%$ and India accounting for $2 \% .{ }^{[15]} \mathrm{A}$ study conducted by Jauniaux et al. found $11(0.12 \%)$ molar pregnancies. ${ }^{[26]}$ In our study, we found only 7 cases $(0.34 \%)$ of Molar pregnancy, which is similar to a study conducted by Uduma et al. found $0.3 \%{ }^{27}$. In the present study, the Blighted ovum was $1.88 \%$ and Uduma et al. found $6.5 \%$. [27]

\section{CONCLUSION}

From the findings of our present study, the commonest ultrasonographic findings in the present study are normal early pregnancy and peak reproductive-age women were 20-24 years old. We also found uterus retroverted in about $7 \%$ of women in early pregnancy and found only 1 (one) case of acute retention of urine due to retroverted gravid uterus. Women presenting with Urinary retention during pregnancy should have a pelvic examination and ultrasonographic examination performed to exclude uterine incarceration. But if it is not diagnosed early and treated properly, it can cause severe complications. USG is also helpful in the diagnosis of normal early pregnancy, abnormal and complicated pregnancies. That's why early diagnosis is the basis of successful treatment and reduces maternal morbidity and mortality.

\section{Acknowledgement}

We would like to thank all the staffs of Failaria and General Hospital (A project of the Institute of Allergy and Clinical Immunology of Bangladesh-a National NGO) for their support during the study and management for permitting us to conduct this study.

\section{REFERENCES}

1. Ultrasound during Pregnancy. http://www.whattoexpect.com/ Pregnancy/ Pregnancy-health prenataltesting/ultrasound aspx, 2016

2. First Trimester/ Dating Ultrasound. http:// www.advancedwomensimaging.com.au/firs t-trimester-dating-ultrasound, 2016 
3. Creanga AA, Shapiro-Mendoza CK, Bish CL, Zane S, Berg CJ, Callaghan WM. Trends in ectopic pregnancy mortality in United States: 1980-2007. Obstet Gynecol 2011;117(4):837-843.

4. Doubilet PM, Benson CB, Bourne T, Blaivas M. Diagnostic criteria for nonviable pregnancy early in the first trimester. Ultrasound Q 2014;30(1),3-9.

5. Weekes ARL, Atlay RD, Brown VA, Murray SM. The retroverted gravid uterus and its effect on the outcome of pregnancy. Br Med J 1976; 1: 622- 4.

6. Gibbons JM, Paley WB. The incarcerated gravid uterus. Obstet Gynecol 1969;33: 842-5.

7. Dierickx I, Meylaerts LJ, Van Holsbeke CD, de Jonge ET, Martens IF, Mesens T, Gyselaers WJ. Incarceration of the gravid uterus: diagnosis and preoperative evaluation by magnetic resonance imaging. Eur J Obstet Gynecol Reprod Biol 2014; 179:191-7.

8. Goldberg KA, Kwart AM. Intermittent urinary retention in first trimester of pregnancy. Urology 1981;17:270-271.

9. Hansen JH, Asmussen M. Acute urinary retention in first trimester of pregnancy. Acta Obstet Gynecol Scand 1985;64:279280.

10. Kondo A, Otani T, Takita T, Hayashi H, Kihira M, Itoh F. urinary retention caused by impaction of a large uterus. Urol Int 1982;37:87-90.

11. Silva PD, Berberich W. Retroverted impacted gravid uterus with acute urinary retention: report of two cases and a review of literature. Obstet Gynecol 1986;68:121124.

12. Swartz EM, Komins JI. Postobstructive diuresis after reduction of an incarcerated, gravid uterus. J Reprod Med 1977;19:2624.

13. Wilcox AJ, Weinberg CR, O'Connor JF, Baird DD, Schlatterer JP, Canfield RE, Armstrong EG, Nisula BC. Incidence of early loss of pregnancy. N Engl J Med. 1988;319(4):189-94.

14. Wang X, Chen C,Wang L, Chen D, Guang W, French J. Conception, early pregnancy loss, and time to clinical pregnancy: a population-based prospective study. Fertil Steril 2003;79:577-584.

15. Kumari S, Kumar B, Singh VK, Pandy RK, Jha H.N, Shahnawaz K. Role of
Ultrasonography in the Diagnosis of Pregnancy. J. Evol. Med. Dent. Sci 2015; 4(22):3774-3780.

16. Nelson MS. Acute urinary retention secondary to an incarcerated gravid uterus. Am J Emerg Med 1986;4: 231-2.

17. Fralick R, Appell RA, Nitti VW. Urodynamics in pelvic prolapsed. In practical Urodynamics, Nitti VW (ed). WB Saunders Philadelphia, PA. 1998;211-218.

18. Francis WJA. Disturbances of bladder function in relation to pregnancy. $\mathrm{Br} \mathrm{J}$ Obstet Gynaecol 1960;72:353

19. Yohannes P. Ultrasound in acute urinary retention and retroverted gravid uterus. Ultrasound Obstet Gynecol 2004;23:427.

20. Rozilza AM, Muhmud HJ. Knowledge, Attitude and practices on Antenatal care among women of jempol, Negeri Sembilan and Malaysian. J Public Health Med 2011; 11:13-21.

21. Shadia SN, Afrin S, Yoshimura K, Hossain $M$. Initiation of Antenatal Care and Number of Antenatal Visit among the pregnant Women of Savar, Dhaka. J Patho Res Rev Rep 2019;1:1;1-4.

22. Cunningham FG, LevenoKJ, Bloom SL, Hauth JC, Gilstrap LC, Wenstrom KD. Diabetes. In: Cunningham FG, LevenoKJ, Bloom SL, Hauth JC,Gilstrap LC, Wenstrom KD Williams Obstetrics, 22 ${ }^{\text {nd }}$ edition. New York: McGraw-Hill 2005; 1169-1187.

23. Newcomb WW, Rodriguez M, Johanson JWC. Reproduction in the older gravid. A literature review. J. Report. Med.1991;36:839-845.

24. Makrydimas G, Sebire NJ, Lolis D, Vlassis $\mathrm{N}$, Nicolaides $\mathrm{KH}$. Fetal loss following ultrasound diagnosis of a live fetus at 6-10 weeks of gestation. Ultrasound Obstet Gynecol 2003; 22(4):1-11.

25. Di Cintio E, Parazzini F, Rosa C, Chatenoud L, Benzi G. The epidemiology of gestational trophoblastic disease. Gen Diagn Pathol 1997;143(2-3):103-108.

26. Jauniaux E, Nicolaides KH. Early ultrasound diagnosis and follow-up of molar pregnancies. Ultrasound Obstet Gynecol 1997;9:17-21.

27. Uduma FU, Abaslattai A, Eduwem DU, Ekanem M, Okere PC. Utility of first trimester obstetric ultrasonography before 13 weeks of gestation: a retrospective study. Pan Afr med 2017,26:121. 